\title{
HOW DO STUDENTS PERCIEVE AND APPRECIATE "FAILURE” DURING UNDERGRADUATE RESEARCH?
}

\author{
Rowland, S. ${ }^{1}$; Tan, C. ${ }^{1}$; Pedwell, R ${ }^{1}$ \\ ${ }^{1}$ School of Chemistry and Molecular Biosciences, The University of Queensland, St \\ Lucia, Queensland, Australia
}

Since 2011 we have conducted Authentic Large-scale Undergraduate Research Experiences (ALURES) with our Sophomore and Junior biochemistry cohorts - so far over 1000 students have participated.

The students in 2011-2014 wrote reflections about their experiences mid-semester and/or at the end of semester. Their writing indicates a growing awareness of the value of failure and struggle, as well as a healthy respect for the power of peer support and interaction.

We asked the question "what do our students see as a "failure", and does their understanding of the value of struggle change as a result of the ALURE experience?

In 2015 we are conducting a longitudinal study of our ALURE students as they progress through the semester - the students have completed a series of five semi-structured interviews and the URSSA survey. We are examining their development of research and scientific literacy through the lens of productive failure.

Our results indicate that although we feel we are designing productive failure into our undergraduate research experiences, we do not appear to be providing a high enough sense of risk or responsibility. This means that the students do not experience a sense of struggle or project ownership with the authenticity we desire. This is causing us to redesign our ALURE offerings. 